\title{
Celastrus orbiculatus extracts induce apoptosis in mTOR-overexpressed human hepatocellular carcinoma HepG2 cells
}

\author{
Yayun Qian ${ }^{1,2,3^{*}+}$, Ting Yang ${ }^{1,4+}$, Xueyu Zhao', Yan Yan ${ }^{1}$, Wenyuan $\mathrm{Li}^{1}$, Chuanci Fang ${ }^{1}$, Jingjing Hou', Li Tao ${ }^{1}$ and \\ Yanqing Liu ${ }^{1,2,3}$
}

\begin{abstract}
Background: Celastrus orbiculatus (Celastraceae) are used as traditional Chinese medicine to treat inflammation and cancer. This study aims to evaluate the effect of Celastrus orbiculatus extract (COE) on the apoptosis in human hepatic carcinoma HepG2 cells with mTOR overexpression.

Methods: The stable expression of mTOR in HepG2 cells (HepG2/mTOR ${ }^{+}$) were established by lipofectin transfection of GV238-mTOR recombinant plasmids and further antibiotic selection. Human hepatic carcinoma HepG2/mTOR ${ }^{+}$cells were treated with different concentrations $(20,40,80,160$, and $320 \mu \mathrm{g} / \mathrm{mL})$ of COE for $24 \mathrm{~h}$. The cell proliferation upon COE treatment was detected by MTT. Apoptosis was measured by Flow Cytometry. The activity of mTOR signaling pathway was detected by Western Blotting.

Results: COE significantly inhibited the proliferation of HepG2/mTOR ${ }^{+}$cells. The expression levels of Bax and Caspase-3 protein were increased in the HepG2/mTOR cells in a dose-dependent manner. The proteins expression of Bcl2, BCl-2 L12, mTOR, phospho-mTOR, 4EBP1, phospho-4EBP1, P70S6k, and phospho-P70S6k in HepG2/mTOR ${ }^{+}$ cells were reduced in dose-dependent manners. Furthermore, COE and mTOR inhibitor rapamycin (RAPA) synergistically induced apoptosis in HepG2/mTOR ${ }^{+}$cells by regulating apoptosis-related proteins and inhibiting mTOR signaling pathways.

Conclusion: COE could inhibit the proliferation of $\mathrm{HepG}_{2} / \mathrm{mTOR}^{+}$cells, and induce the cell apoptosis. The mechanisms may be related to the regulation of the expression of $\mathrm{BCl}-2, \mathrm{BCl}-2 \mathrm{~L} 12$, and mTOR signaling pathways. These data suggest that COE may be a potential treatment for human hepatocellular carcinoma.
\end{abstract}

Keywords: Celastrus orbiculatus, Hepatocellular carcinoma, mTOR, Apoptosis

\section{Background}

Hepatocellular carcinoma (HCC) is one of the most common malignant tumors in the world [1]. In recent years, the incidence and mortality rate of HCC is increasing. Despite multimodal therapies, including surgery, chemotherapy, and radiotherapy, the curative effect on HCC patients is not as good as anticipated [2].

\footnotetext{
* Correspondence: yyqian@yzu.edu.cn

†Yayun Qian and Ting Yang contributed equally to this work.

${ }^{1}$ Institute of Traditional Chinese Medicine \& Western Medicine, School of Medicine, Yangzhou University, 11 Huaihai Road, Yangzhou 225009, China ${ }^{2}$ Jiangsu Key Laboratory of Integrated Traditional Chinese and Western Medicine for Prevention and Treatment of Senile Diseases, Yangzhou 225001, China

Full list of author information is available at the end of the article
}

Recent studies of new anti-metastatic agents have demonstrated that some Chinese herbs with chemopreventive capability can slow down the metastasis of several types of cancer [3, 4]. Previous studies showed that the ethyl acetate extract of Celastrus orbiculatus extract (COE) exhibited many significant anti-tumor bioactivities, such as inhibiting proliferation and inducing apoptosis [5-7]. Mechanistic target of rapamycin (mTOR) is associated with poorly differentiated tumors and bad prognosis. The two mTOR-containing complexes (mTORC1 and mTORC2 pathways) that involve pRPS6 and p-AKT are up-regulated by $40-50 \%$ in HCCs [8]. Thus, blocking the mTOR signal pathway is an attractive strategy for HCC treatment. Preliminary experimental

(c) The Author(s). 2018 Open Access This article is distributed under the terms of the Creative Commons Attribution 4.0 International License (http://creativecommons.org/licenses/by/4.0/), which permits unrestricted use, distribution, and reproduction in any medium, provided you give appropriate credit to the original author(s) and the source, provide a link to the Creative Commons license, and indicate if changes were made. The Creative Commons Public Domain Dedication waiver (http://creativecommons.org/publicdomain/zero/1.0/) applies to the data made available in this article, unless otherwise stated. 
studies have revealed that COE has a significant inhibitory effect [9-13] on the epithelialmesenchymal transition (EMT), invasion, and metastasis, and inhibits the growth of several types of cancer cells. The preliminary results of our study suggest that $\mathrm{COE}$ can inhibit the activity of the mTOR signaling pathway [14], but the underlying molecular mechanism has not been revealed completely. This study explored the effects of $\mathrm{COE}$ on the proliferation and apoptosis in the $\mathrm{HepG} / \mathrm{mTOR}^{+}$ cells, which may bring new hope for clinical treatment of cancer characterized with mTOR activation.

\section{Materials and methods}

\section{Preparation of extract}

The dried stems of the $C$. orbiculatus were provided by Zhixin Pharmaceutical Co., Ltd. (Guangzhou, China). As described previously [5, 9-14], the authentication and preparation of COE was made by professor Wangqiang (China Pharmaceutical University) [15]. Briefly, the powder of the herb was extracted with 10 -fold of $95 \%$ ethanol under heat for $3 \mathrm{~h}$ three times and the mixtures were filtered and concentrated. Then the obtained extractions from ethyl acetate were concentrated using a rotary evaporator and stored at $-20^{\circ} \mathrm{C}$. Before use, the extracts were dissolved in DMSO with the final concentration of DMSO not exceeding $0.1 \%$. The positive control drug, Cisplatin (abbreviated to DDP, $2 \mathrm{mg} / \mathrm{L}$ ), was product of Haosen Pharmaceutical Co., Ltd. (Jiangsu, China) [16].

\section{Chemical reagents and antibodies}

DMEM and fetal bovine serum (FBS) was obtained from GIBCO-BRL (Gaithersburg, MD, USA). The antibodies, including rabbit $\beta$-actin, mTOR, phospho-mTOR, 4E-BP1, phospho-4E-BP1, P70S6k, and phospho-P70S6k were purchased from Cell Signaling Technology (Beverly, MA). Rabbit Bax antibody was acquired from Santa Cruz in USA. Rabbit Bcl-2, Bcl-2 L12, and Caspase-3 antibody from American Epitomics Company were also obtained. HRP labeled goat anti-rabbit IgG was purchased from Hangzhou Huaan Biotechnology Co.

\section{Cell culture}

Human hepatocellular carcinoma HepG2 cells were obtained from the Cell Bank of Chinese Academy of Sciences Shanghai Institute of Cell Biology (Shanghai, China). The HepG2 Cells with high expression of mTOR, termed as HepG2/mTOR ${ }^{+}$, were constructed by our laboratory. The cells were cultured in DMEM which was supplemented with $10 \% \mathrm{FBS}$ at $37^{\circ} \mathrm{C}$ in a humidified incubator containing $5 \% \mathrm{CO}_{2}$.

\section{Cell viability assay}

The cell viability was determined using MTT assay. HepG2/mTOR ${ }^{+}$were inoculated at a density of $1 \times 10^{4}$ cells per well in 96-well plates, treated with $\mathrm{COE}$ at various concentrations $(20,40,80,160$ and $320 \mu \mathrm{g} / \mathrm{mL})$. The cell incubated only DMSO was considered as the negative control. The incubation was continued for 24 , 48 , and $72 \mathrm{~h}$, respectively. Subsequently, $20 \mu \mathrm{L}$ of MTT was added to plates and incubated for another $4 \mathrm{~h}$. The supernatant was gently discarded and replaced with $150 \mu \mathrm{L}$ DMSO to dissolve the formazan crystal. The absorbance (A) value was detected at $490 \mathrm{~nm}$. Each experiment was repeated for three times.

\section{Flow cytometry}

HepG2/mTOR ${ }^{+}$Cells treated with different concentrations of COE for $24 \mathrm{~h}$, cells were washed with PBS by centrifugation for $5 \mathrm{~min}$. Subsequently, cells were incubated with $5 \mu \mathrm{L}$ Annexin V-FITC and $5 \mu \mathrm{L}$ PI or FITC isotype control for $30 \mathrm{~min}$ at $4{ }^{\circ} \mathrm{C}$ in the dark. The levels of fluorescence were analyzed with FACSort software (Becton-Dickinson, USA). Each assay was performed with three independent experiments.

\section{Western blot analysis}

HepG2/mTOR ${ }^{+}$Cells were incubated with different concentrations of COE for $24 \mathrm{~h}$. The total proteins, extracted with cell lysis buffer (Beyotime, Jiangsu, China) for $30 \mathrm{~min}$ on ice, were quantified by NanoPhotometer pearl (IMPLEN, Germany). $50 \mu \mathrm{g}$ of total protein were separated on $10 \%$ SDS-PAGE for electrophoresis, and then transferred to PVDF membranes. The membranes were blocked with 5\% BSA for $2 \mathrm{~h}$, and then incubated with appropriate primary antibodies overnight at $4{ }^{\circ} \mathrm{C}$. The following day, the membranes were incubated with the secondary antibody for $2 \mathrm{~h}$ and detected by using the ECL reagent.

\section{Statistical analysis}

All experiments were performed in triplicate, and the results are presented as mean \pm standard deviation. Statistical analysis was carried out with GraphPad Prism 5.0 Software. The unpaired Student's $t$-test was used to determine $P$-values for the differences. Results were considered significantly different when $P<0.05$.

\section{Results}

Establishment of the stable HepG2 cell line with mTOR overexpression

The GV238 vector with Luciferase reporter gene was digested with $M l u \mathrm{I}$ and $B g l \mathrm{II}$. And then the mTOR (NM_004958) promotor genes were cloned into GV238 vector by using molecular biological technology (Fig. 1a). The GV238-mTOR recombinant plasmids were transfected into HepG2 cells, named as HepG2/mTOR ${ }^{+}$cells, with using transfected GV238 vehicle HepG2 cells as control [17]. HepG2/mTOR ${ }^{+}$cells in logarithmic growth 
A

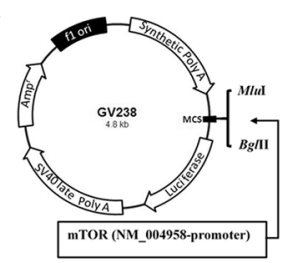

C

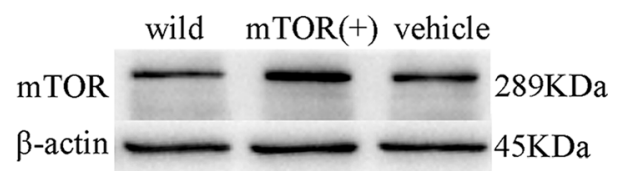

B
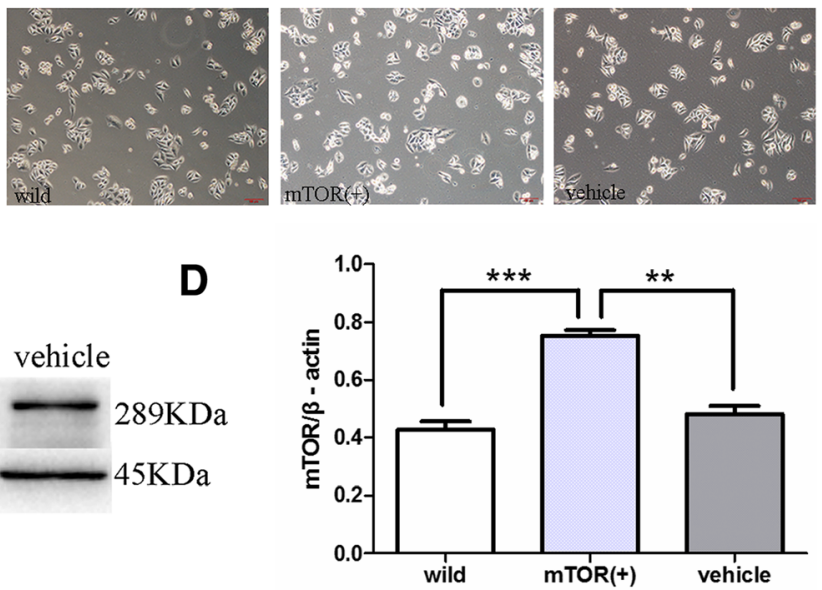

Fig. 1 Generation of the HepG2/mTOR ${ }^{+}$cells. a Construction of the GV238-mTOR recombinant plasmid. $\mathbf{b}$ cell morphology under a microscope (100x). $\mathbf{c}$ and $\mathbf{d}$ the expression levels of mTOR in the HepG2/mTOR ${ }^{+}$cells. $\left(^{* *} P<0.01\right.$, versus vehicle; ${ }^{* * *} P<0.001$, versus wild type)

phase were seeded in a 6 -well plate at $5 \times 10^{4} /$ well. The cell morphology has no appreciable difference after mTOR gene transfection under a microscope (100× magnification) (Fig. 1b). The mTOR protein expression was detected by western blots. Compared to the wild type HepG2 cells, the mTOR protein expression in HepG2/ $\mathrm{mTOR}^{+}$cells were significantly increased (Fig. 1c, d). These results showed that we had successfully established a stable HepG2 cell line with overexpressed mTOR.

\section{COE inhibited the viability in the HepG2/ $\mathrm{mTOR}^{+}$cells}

After adding different concentrations of COE (20,40, 80, 160 , and $320 \mathrm{mg} / \mathrm{L}$ ), the cell viability was investigated by MTT for 24, 48, and $72 \mathrm{~h}$, respectively. Compared with the vehicle and wide type HepG2 cells, the growth of untreated HepG2/mTOR ${ }^{+}$cells has not shown any significant difference. On the other hand, in the treated groups, the growth of $\mathrm{HepG} 2 / \mathrm{mTOR}^{+}$cells was inhibited significantly in a dose-dependent and time-dependent manner (Fig. 2). The half inhibitory concentration of COE for $24 \mathrm{~h}$ was $126 \mathrm{mg} / \mathrm{L}$. In order to decrease the cytotoxicity of the drug, the concentrations $(20,40$, and $80 \mathrm{mg} / \mathrm{L})$ of $\mathrm{COE}$ were selected for further study.

\section{Morphology of the HepG2/ mTOR ${ }^{+}$cells}

Phase-contrast images of cells from the same fields were taken $24 \mathrm{~h}$ after the treatment of COE. Representative pictures of $\mathrm{HepG} / \mathrm{mTOR}^{+}$cells showed that the viability was significantly decreased (Fig. 3a, b). Transmission electron microscopy demonstrated that there were many

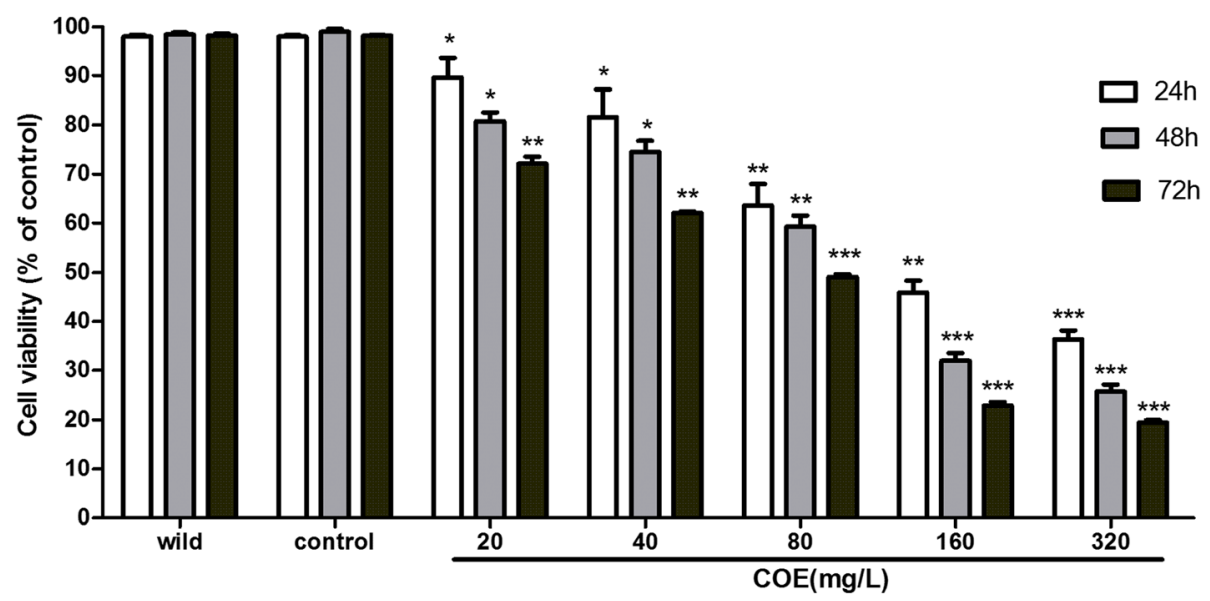

Fig. 2 Effects of COE on the viability of the HCC cells. The HepG2/mTOR ${ }^{+}$cells were treated with either $0.1 \% \mathrm{DMSO}$ as solvent control or different concentrations of $\operatorname{COE}(20,40,80,160$, and $320 \mathrm{mg} / \mathrm{L})$ for 24,48 , and $72 \mathrm{~h}$, respectively, and the cell viability was evaluated with MTT assay. $\left({ }^{*} P<0.05,{ }^{* *} P<0.01,{ }^{* * *} P<0.001\right.$, compared with the solvent control) 


\section{A}

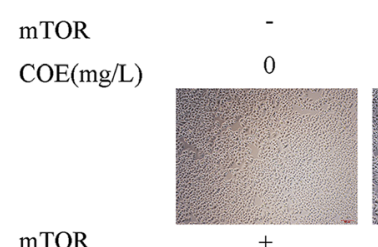

$\operatorname{COE}(\mathrm{mg} / \mathrm{L})$

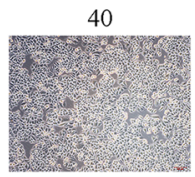

C

$$
\text { mTOR }
$$

COE $(\mathrm{mg} / \mathrm{L})$

mTOR

$\mathrm{COE}(\mathrm{mg} / \mathrm{L})$

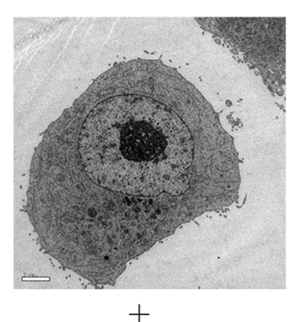

40

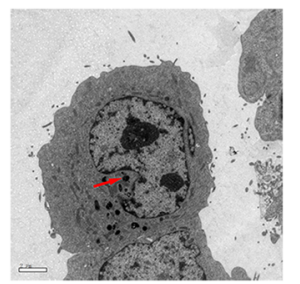

B

$+$

20

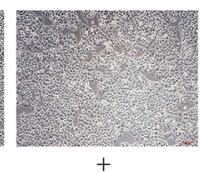

DDP

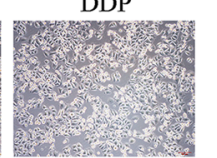

$+$

0

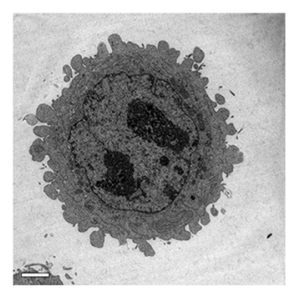

$+$

80

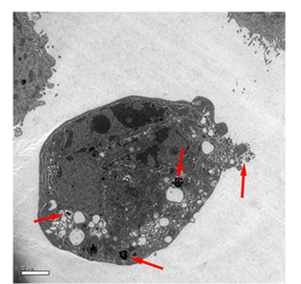

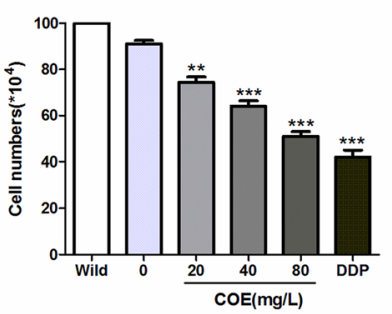

$+$

20

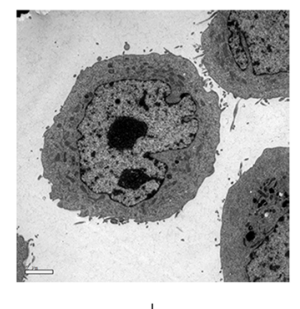

DDP

Fig. 3 Effects of COE on cellular morphology of the HCC cells. The HepG2/mTOR ${ }^{+}$cells were treated with 0.1\%DMSO as solvent control, or 2 mg/ L DDP, or different concentrations of $\operatorname{COE}(20,40$, and $80 \mathrm{mg} / \mathrm{L})$ for $24 \mathrm{~h}$. a and $\mathbf{b}$ the HepG2/mTOR cells were observed under inverted microscope and taken phase-contrast images from the same fields $(100 \mathrm{x})$. $\mathbf{c}$ the morphological changes were observed under transmission electron microscope $(2950 \times$, Scale, $1 \mu \mathrm{m})$; red arrows are representative of the apoptotic bodies. $\left({ }^{* *} P<0.01,{ }^{* * *} P<0.001\right.$, compared with the vehicle)

microvilli and fenestrations on the cellular surface of the wide type HepG2 cells. There were many organelles in the cytoplasm, and the mitochondria were regular. After the treatment of $\mathrm{COE}$, the cytoplasm was concentrated, the cell membrane was bubbled, and the apoptotic bodies were produced (Fig. 3c). It was shown that some cells were necrotic, and the cell membranes ruptured with the contents were released.

\section{COE induced the apoptosis in HepG2/ $\mathrm{mTOR}^{+}$cells}

After adding different concentrations of $\operatorname{COE~}(20,40$, and $80 \mathrm{mg} / \mathrm{L}$ ) for $24 \mathrm{~h}$, apoptosis was detected by flow cytometric analysis ( $2 \mathrm{mg} / \mathrm{L}$ DDP was used as the positive control drug). There was no significant difference between the wild type HepG2 cells and HepG2/mTOR ${ }^{+}$ cells. And the results showed that after the drug treatment, the percentage of the apoptotic $\mathrm{HepG} 2 / \mathrm{mTOR}^{+}$ cells was significantly increased in a dose-dependent manner (Fig. 4a, b). The results of Western blots showed that COE increased the expression of Bax and Caspase-3. Meanwhile, COE decreased the expression of $\mathrm{Bcl}-2$ and $\mathrm{Bcl}-2 \mathrm{~L} 12$ in a concentration-dependent manner, especially reducing the ratio of $\mathrm{Bcl}-2 / \mathrm{Bax}$ (Fig. 4c-e). It indicated that COE induced the apoptosis of the HepG2/mTOR ${ }^{+}$cells in a concentration-dependent manner.

\section{COE effects on the mTOR signaling pathway}

After adding different concentrations of COE (20, 40, and $80 \mathrm{mg} / \mathrm{L}$ ) for $24 \mathrm{~h}$, the protein expression correlated mTOR signaling pathways were determined by Western blots $(2 \mathrm{mg} / \mathrm{L}$ DDP was used as the positive control 
A

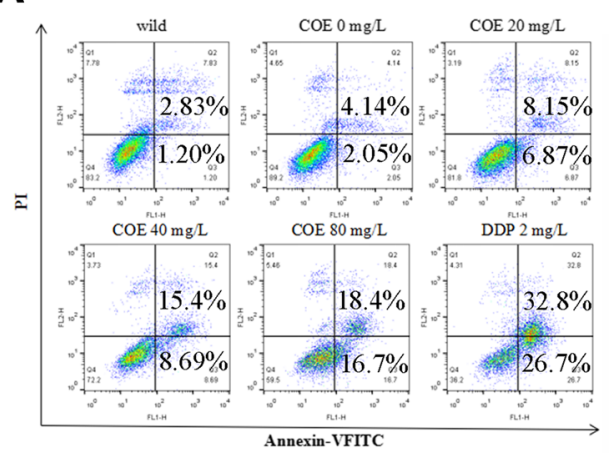

C

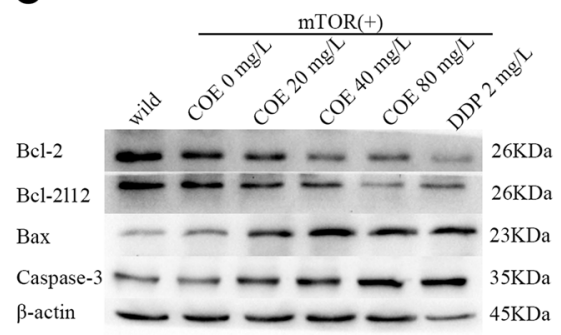

$\mathbf{E}$

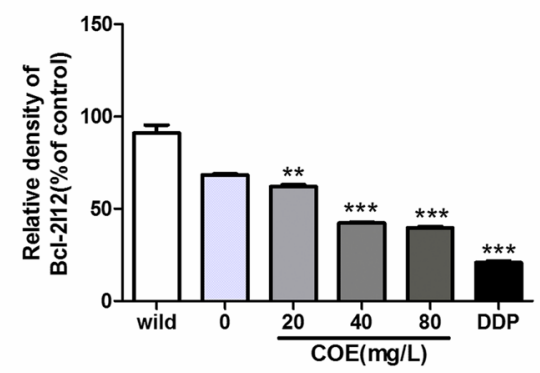

B

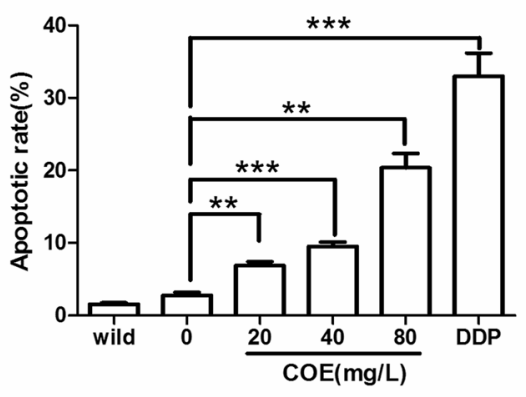

D

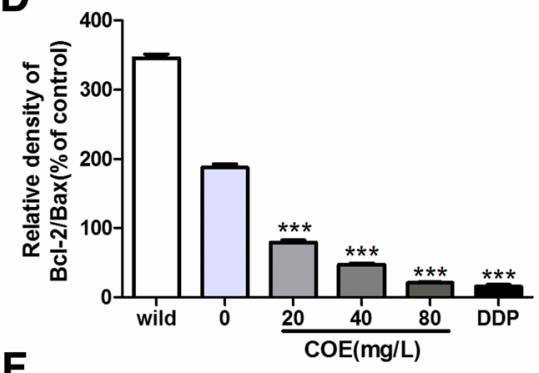

$\mathbf{F}$

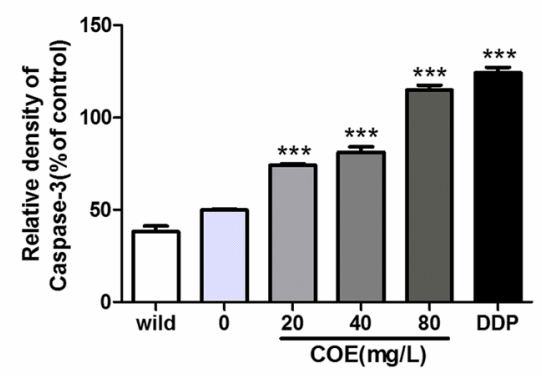

Fig. 4 COE promoted apoptosis of the HCC cells. The HepG2/mTOR ${ }^{+}$cells were treated with $0.1 \% D M S O$ as solvent control, or 2 mg/L DDP, or different concentrations of $\operatorname{COE}(20,40,80 \mathrm{mg} / \mathrm{L})$ for $24 \mathrm{~h}$. $\mathbf{a}$ and $\mathbf{b}$ the apoptosis was detected by Flow cytometry. $\mathbf{c}-\mathbf{f}$ the protein expression of BCl-2, BCl-2 L12, Bax, and Caspase-3 were examined by Western blots. $\left({ }^{* *} P<0.01,{ }^{* * *} P<0.001\right.$, compared with the vehicle)

drug). Compared to the untreated control, in HepG2/ $\mathrm{mTOR}^{+}$cells, the protein levels of mTOR, p-mTOR and its downstream proteins such as 4EBP1, p-4EBP1, P70S6k, and p-P70S6k, were reduced significantly in both dose-dependent and time-dependent manners after COE treatment (Fig. 5).

The mTOR signaling pathway is a master regulator of cell growth and metabolism. Dysregulation of the mTOR pathway has been implicated in a number of human diseases such as cancer, diabetes, obesity, neurological diseases, and genetic disorders. Rapamycin (RAPA), a specific inhibitor of mTOR, has been shown to be effective in treating several diseases [18]. In order to confirm whether COE has a synergistic effect with mTOR inhibitors and induces apoptosis via mTOR signaling pathways in $\mathrm{HepG} 2 / \mathrm{mTOR}^{+}$cells, we used $100 \mathrm{nmol} / \mathrm{L}$ RAPA to observe the effects of COE on apoptosis. The results showed that COE reduced the cell number (Fig. 6a, b) and induced apoptosis (Fig. 6d-g) in HepG2/mTOR ${ }^{+}$ cells. The cell morphology was observed by transmission electron microscopy after the co-treatment of RAPA and COE. The cell membranes were ruptured and the contents were released (Fig. 6c). The expression levels of the proteins that are involved in mTOR signaling pathways were changed significantly. Compared with the treatment with COE or RAPA alone, the co-treatment of COE and RAPA showed a synergistic effect in HepG2/ $\mathrm{mTOR}^{+}$cells (Fig. 6h, i). Taken together, these data revealed that $\mathrm{COE}$ could further promote tumor cell apoptosis when mTOR signaling pathways are suppressed.

\section{Discussion}

Many extracts derived from herbs have been tested as inhibitors of cancer cell proliferation both in vitro and in 

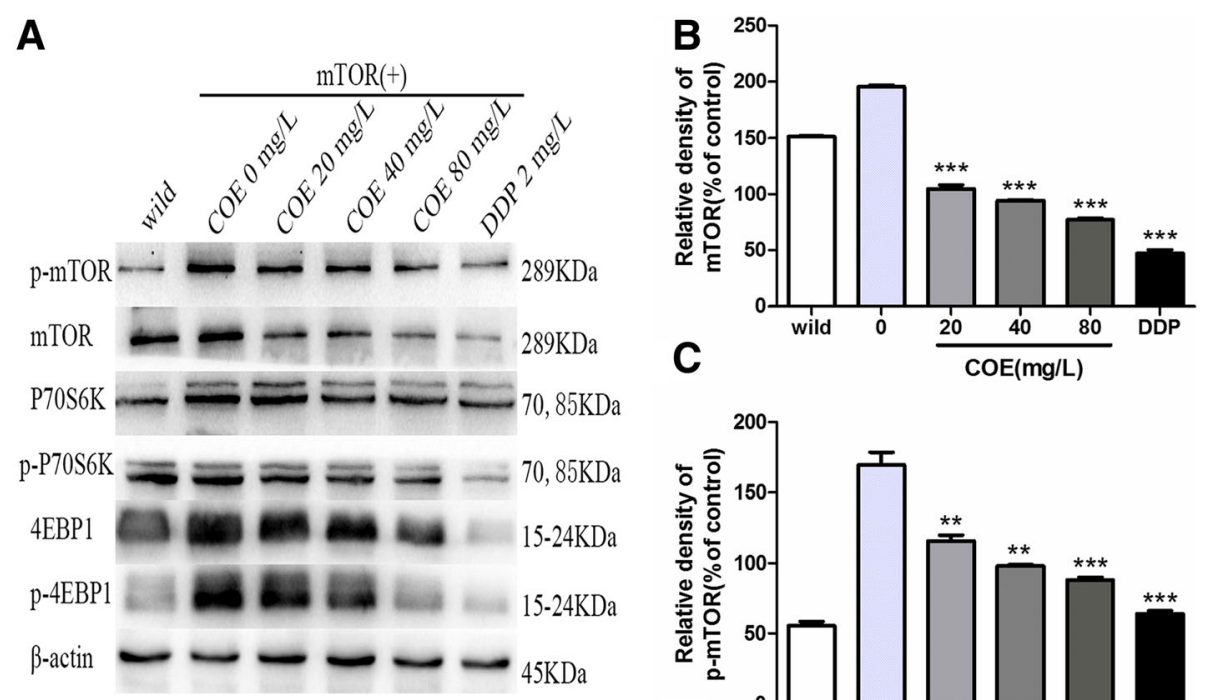

D
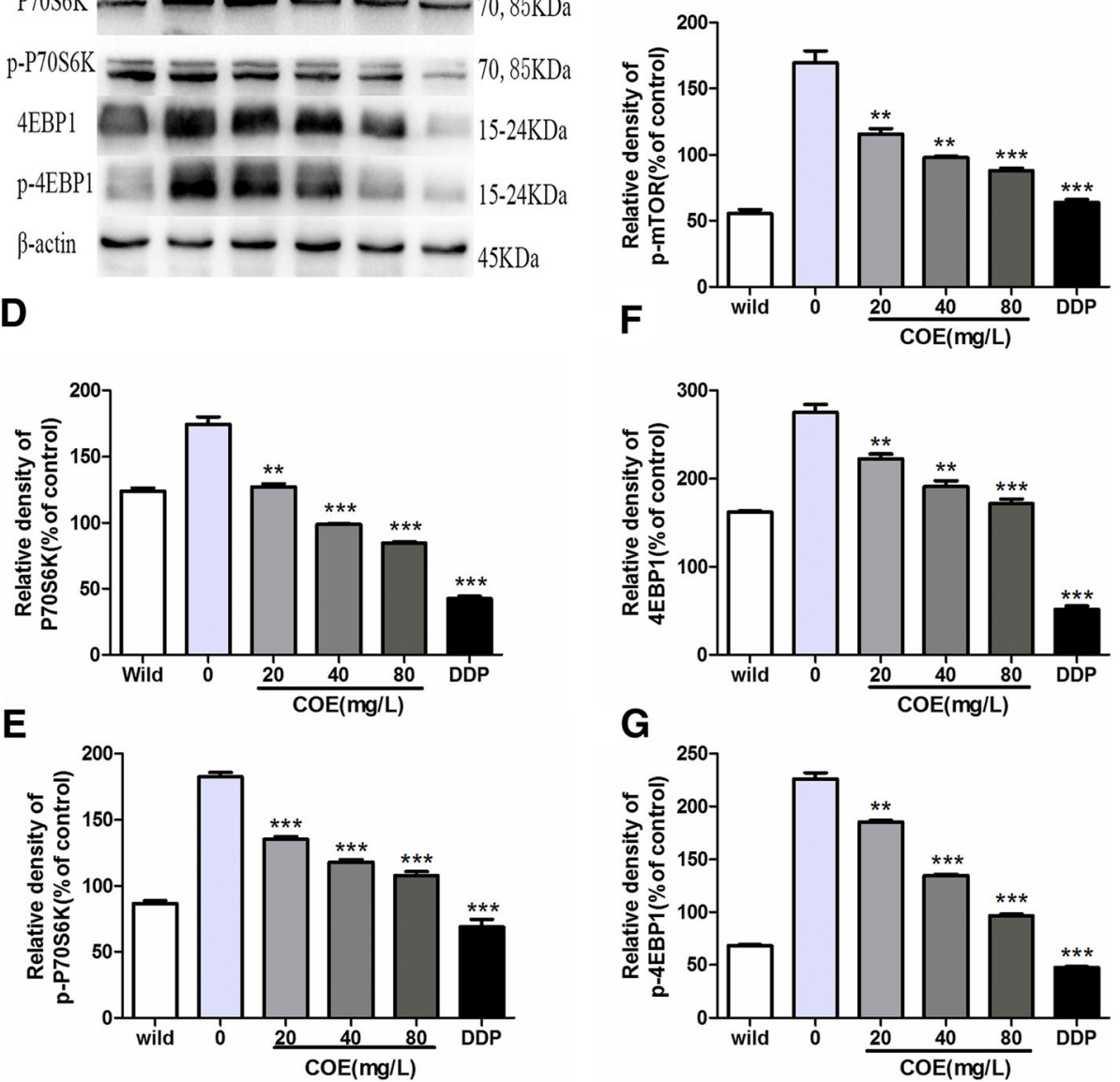

Fig. 5 Expression of the proteins that are involved in the mTOR signaling pathways. The HepG2/mTOR ${ }^{+}$cells were treated with $0.1 \% \mathrm{DMSO}$ as solvent control, or $2 \mathrm{mg} / \mathrm{L}$ DDP, or different concentrations of $\operatorname{COE}(20,40$, and $80 \mathrm{mg} / \mathrm{L})$ for $24 \mathrm{~h}$. The proteins expression of mTOR, p-mTOR, 4E-BP1, p-4E-BP1, P70S6K, and p-P70S6K were studied by Western blot analysis. ${ }^{* *} P<0.01,{ }^{* * *} P<0.001$, compared with the vehicle control)

vivo [19-21]. The preliminary results of our study have demonstrated that $\mathrm{COE}$ is cytotoxic to various cancer cells including human glioblastoma cells [11], hepatocellular carcinoma [5-7], and human gastric cancer $[9,10,12,13]$. Mammalian target of rapamycin (mTOR) is a class of non-conserved evolutionary protein kinase, and involved in a variety of physiological and pathological processes, such as cell proliferation, cell differentiation, autophagy, angiogenesis, etc [22-25]. The two mTOR-containing complexes (mTORC1 and mTORC2) have different sensitivities to rapamycin. mTORC1 is inhibited by a complex consisted of rapamycin and FKBP12 protein [26]. In contrast, mTORC2 is generally resistant to rapamycin, however, in certain cell types, mTORC2 may show sensitivity after prolonged rapamycin treatment [27]. Accumulated evidence supports that there are mutations, amplifications, or deletions of mTOR signaling pathways in many tumors. These proteins can cause over-activation of mTOR pathways, leading to abnormal tumor cell proliferation [28]. Clinical specimens from patients with hepatocellular carcinoma were analyzed by using immunohistochemistry [29]. The results showed that the expression level of mTOR is 


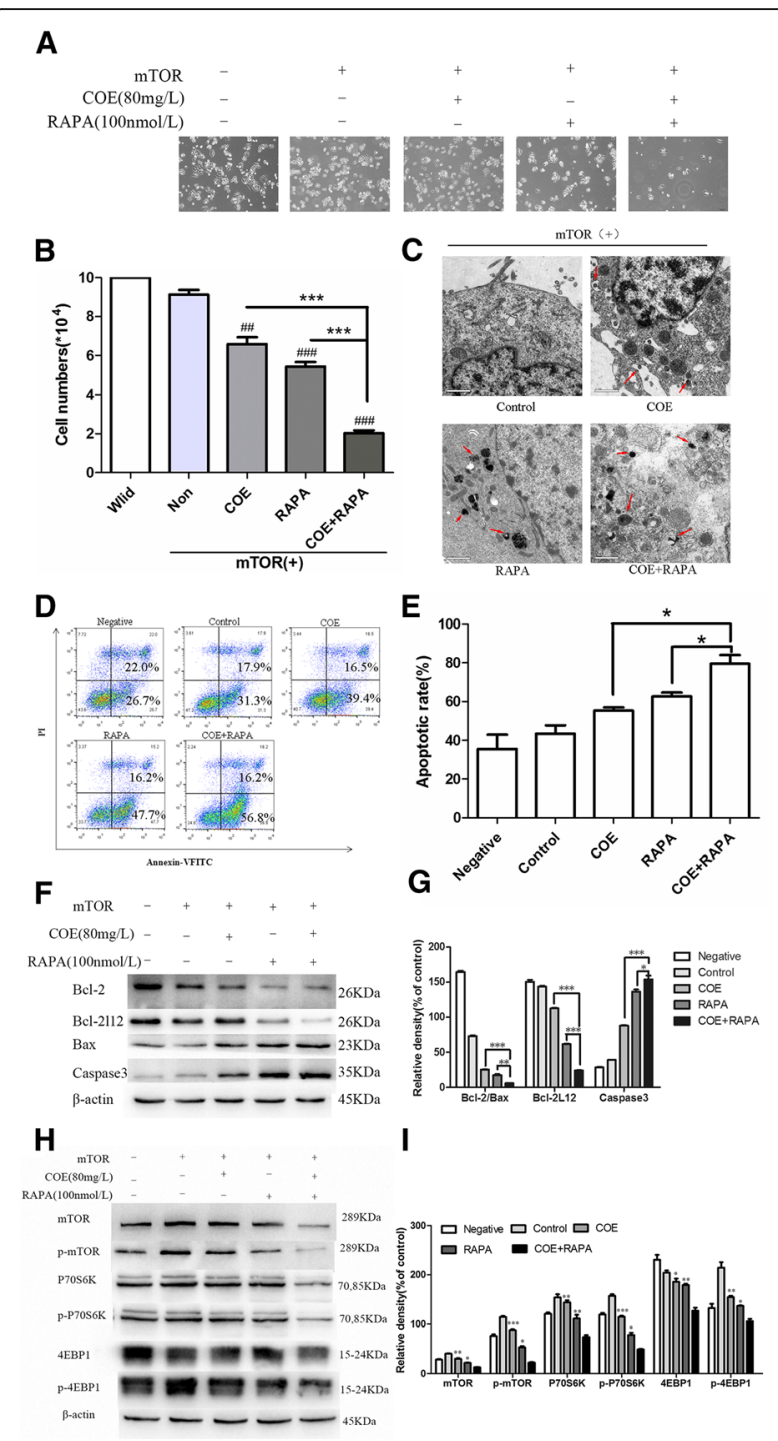

Fig. 6 Effects of the combined treatment of RAPA and COE. The $\mathrm{HepG}_{2} / \mathrm{mTOR}^{+}$cells were treated with $0.1 \% \mathrm{DMSO}$ as solvent control, or $80 \mathrm{mg} / \mathrm{L} \mathrm{COE}$, or $100 \mathrm{nmol} / \mathrm{L}$ RAPA combined with $80 \mathrm{mg} / \mathrm{L} \mathrm{COE}$ for $24 \mathrm{~h}$. $\mathbf{a}$ and $\mathbf{b}$ the numbers of the HepG $2 / \mathrm{mTOR}^{+}$cells were observed under inverted microscope (100x). c the morphological changes were observed under transmission electron microscope (2950X, Scale, $1 \mu \mathrm{m}$ ); red arrows are representative of the apoptotic bodies. $\mathbf{d}$ and $\mathbf{e}$ the apoptosis was detected by Flow cytometry. $\mathbf{f}$ and $\mathbf{g}$ the proteins expression of $\mathrm{BCl}-2, \mathrm{BCl}-2 \mathrm{~L} 12, \mathrm{Bax}$, and Caspase-3 were examined by Western blots. $\mathbf{h}$ and $\mathbf{i}$ the proteins expression of mTOR, p-mTOR, 4E-BP1, p-4E-BP1, P70S6K, and p-P70S6K were accessed by Western blots. $\left({ }^{*} P<0.05,{ }^{* *} P<0.01,{ }^{* * *} P<0.001\right.$, COE + RAPA group compared with COE or RAPA alone; ${ }^{\# \#} P<0.01$, ${ }^{\# \# \# P}<0.001$, compared to the control)

higher than that in the adjacent non-tumor liver tissue, and protein expression level of mTOR was positively correlated with malignancy and poor prognosis. This suggests that mTOR may be a potential target for the treatment of hepatocellular carcinoma. Biomarkers for mTOR inhibitor efficacy have been evaluated in both preclinical and clinical studies. Our data identified that $\mathrm{COE}$ is able to inhibit mTOR signaling pathways.

The Bcl-2 family is the key factor in the mitochondria-mediated signal pathway of apoptosis [30]. $\mathrm{Bcl}-2$ is an inhibitor of apoptosis, preventing the release of mitochondrial cytochrome c, while Bax is a pro-apoptotic factor that in turn promotes its release. Bcl-2 L12 has been discovered as a new gene of Bcl-2 family which can inhibit apoptosis of tumor cell [31, 32] and was found to be over-expressed in tumor tissue [33]. Caspase-3 is another important terminal cleaving enzyme in the process of cell apoptosis [34]. This study indicated that $\mathrm{COE}$ could reduce the expression of $\mathrm{Bcl}-2$ protein and increase the expression of $B a x$ and Casepase- 3 total protein, while the ratio of $\mathrm{Bcl}-2 / \mathrm{Bax}$ was decreased. Therefore, COE played a pro-apoptotic role through the Bcl-2, Bax, and Casepase-3-mediated signaling pathway. The results of the present study demonstrated that $\mathrm{COE}$ inhibited the proliferation of $\mathrm{HepG} 2 / \mathrm{mTOR}^{+}$cells and induced apoptosis in a concentration-dependent manner. Furthermore, the combination of COE and RAPA synergistically induced apoptosis in HCC cells by regulating apoptosis-related proteins and inhibiting the mTOR signaling pathways.

\section{Conclusion}

In summary, COE contributed to promote apoptosis of HepG2/mTOR ${ }^{+}$cells, which was closely related to Bcl-2 family. Also, COE was able to suppress the mTOR signaling pathways. Nevertheless, in vivo data are still required for further verifying our findings. Altogether, the present study reveals that $\mathrm{COE}$ can be considered as a potential antineoplastic drug for treating hepatocellular carcinoma.

\section{Abbreviations}

COE: Celastrus orbiculatus extract; HCC: Hepatocellular carcinoma; RAPA: Rapamycin

\section{Acknowledgements}

L.T is very grateful to the Yangzhou University for the postdoctoral fellowship.

\section{Funding}

This study was supported by the National Natural Science Foundation of China (No. 81403232, to Y.Y.Q); National Natural Science Foundation of Jiangsu Province (Nos.BK20171290 and BK2012686, to Y.Y.Q); Doctoral Fund of Ministry of Education of China (No.20133250120003, to Y.Y.Q) and Natural Science Foundation of Jiangsu Province for Youths (No.BK20170516, to L.T). The funder had no implication in the design of the study, collection, analysis and interpretation of data; and in writing the manuscript; and the decision to submit the article for publication.

\section{Availability of data and materials}

The dataset supporting the conclusions of this article are included within the article. The datasets used and/or analyzed during the current study are available from the corresponding author on reasonable request. 


\section{Authors' contributions}

Y.Y.Q designed the research and wrote the manuscript, Y.Y.Q, T.Y, X.Y.Z, Y.Y, W.Y.L, C.C.F and J.J.H performed and analyzed experiments. T.Y, L.T performed computational analyses. Y.Y.Q provided technical assistance. Y.Q.L conceived, designed and supervised the study. All authors edited or commented on the manuscript. All authors read and approved the final manuscript.

\section{Ethics approval and consent to participate}

Not applicable.

\section{Consent for publication}

Not applicable.

\section{Competing interests}

The authors declare that they have no competing interests.

\section{Publisher's Note}

Springer Nature remains neutral with regard to jurisdictional claims in published maps and institutional affiliations.

\section{Author details \\ 'Institute of Traditional Chinese Medicine \& Western Medicine, School of Medicine, Yangzhou University, 11 Huaihai Road, Yangzhou 225009, China. ${ }^{2}$ Jiangsu Key Laboratory of Integrated Traditional Chinese and Western Medicine for Prevention and Treatment of Senile Diseases, Yangzhou 225001, China. ${ }^{3}$ Jiangsu Co-innovation Center for Prevention and Control of Important Animal Infectious Diseases and Zoonoses, Yangzhou 225009, China. ${ }^{4}$ Changzhou Hospital of Traditional Chinese Medicine, Changzhou 213000, China.}

\section{Received: 17 October 2017 Accepted: 29 November 2018} Published online: 07 December 2018

\section{References}

1. Buendia MA, Neuveut C. Hepatocellular carcinoma. Cold Spring Harb Perspect Med. 2015;5(2):a021444.

2. Gordon RR, Nelson PS. Cellular senescence and cancer chemotherapy resistance. Drug Resist Updat. 2012;15(1-2):123-31.

3. Liu YH, Li ML, Hsu MY, et al. Effects of a Chinese herbal medicine, Guan-JenHuang (Aeginetia indica Linn.), on renal cancer cell growth and metastasis. Evid Based Complement Alternat Med. 2012;2012:935860

4. Wu B, Hu K, Li S, et al. Dihydroartiminisin inhibits the growth and metastasis of epithelial ovarian cancer. Oncol Rep. 2012;27(1):101-8.

5. Qian YY, Zhang H, Hou Y, et al. Celastrus orbiculatus extract inhibits tumor angiogenesis by targeting vascular endothelial growth factor signaling pathway and shows potent antitumor activity in hepatocarcinomas in vitro and in vivo. Chin J Integr Med. 2012;18(10):752-60.

6. Wang $M$, Zhang $X$, Xiong $X$, et al. Efficacy of the Chinese traditional medicinal herb Celastrus orbiculatus Thunb on human hepatocellular carcinoma in an orthothopic fluorescent nude mouse model. Anticancer Res. 2012;32(4):1213-20.

7. Zhang $\mathrm{H}$, Qian $\mathrm{Y}$, Liu Y, et al. Celastrus orbiculatus extract induces mitochondrial-mediated apoptosis in human hepatocellular carcinoma cells. J Tradit Chin Med. 2012;32(4):621-6

8. Matter MS, Decaens T, Andersen JB, Thorgeirsson SS. Targeting the mTOR pathway in hepatocellular carcinoma: current state and future trends. J Hepatol. 2014:60(4):855-65.

9. Zhu Y, Liu Y, Qian Y, Dai X, Yang L, Chen J, Guo S, Hisamitsu T. Antimetastatic effects of Celastrus orbiculatus on human gastric adenocarcinoma by inhibiting epithelial-mesenchymal transition and NF-KB/ snail signaling pathway. Integr Cancer Ther. 2015;14(3):271-81.

10. Zhu Y, Liu Y, Qian Y, Dai X, Yang L, Chen J, Guo S, Hisamitsu T. Research on the efficacy of Celastrus Orbiculatus in suppressing TGF- $\beta 1$-induced epithelial-mesenchymal transition by inhibiting HSP27 and TNF-a-induced $\mathrm{NF}-\mathrm{k} \mathrm{B} /$ snail signaling pathway in human gastric adenocarcinoma. BMC Complement Altern Med. 2014;14:433.

11. Gu H, Feng J, Wang H, Qian Y, Yang L, Chen J, Jin F, Shi Y, Lu S, Liu Y. Celastrus orbiculatus extract inhibits the migration and invasion of human glioblastoma cells in vitro. BMC Complement Altern Med. 2016;16(1):387.
12. Wang H, Tao L, Ni T, Gu H, Jin F, Dai X, Feng J, Ding Y, Xiao W, Guo S, Hisamitsu T, Qian Y, Liu Y. Anticancer efficacy of the ethyl acetate extract from the traditional Chinese medicine herb Celastrus orbiculatus against human gastric cancer. J Ethnopharmacol. 2017:205:147-57.

13. Qian Y, Lu S, Shi Y, Zhao X, Yang T, Jin F, Liu Y. Celastrus orbiculatus extracts induce apoptosis and inhibit invasion by targeting the maspin gene in human gastric adenocarcinoma cells. Oncol Lett. 2018;15(1):243-9.

14. Yayun Q, Feng J, Ling C, et al. Effect of Celastrus Orbiculatus extract on epithelial-mesenchymal transition in HepG2 cells. World Science and Technology. 2014;16(12):2647-51.

15. Ke Z, Xiaoging C, Wang Q, et al. Studies on chemical composition of Celastrus orbiculatus stems. Chinese herbal medicine. 2007;38(10):1455-8.

16. Zhao S, Zhang Y, Wu C, et al. 3-bromopyruvate enhances cisplatin sensitivity of hepatocellular carcinoma cells in vitro. Nan Fang Yi Ke Da Xue Xue Bao. 2014:34(1):25-30

17. Qian YY, Lu SH, Zhao XY, et al. Effects of Celastrus orbiculatus Thunb. Extract on the overexpression of mTOR in human HepG2 cells. World Science and Technology/Modernization of Traditional Chinese Medicine and Materia Medica. 2016;18(12):2132-6.

18. Li J, Kim SG, Blenis J. Rapamycin: one drug, many effects. Cell Metab. 2014; 19(3):373-9.

19. Yeon Park J, Young Kim H, Shibamoto T, Su Jang T, Cheon Lee S, Suk Shim J, Hahm DH, Lee HJ, Lee S, Sung KK. Beneficial effects of a medicinal herb, Cirsium japonicum var. maackii, extract and its major component, cirsimaritin on breast cancer metastasis in MDA-MB-231 breast cancer cells. Bioorg Med Chem Lett. 2017:27(17):3968-73.

20. Yao H, Chen B, Zhang Y, Ou H, Li Y, Li S, Shi P, Lin X. Analysis of the Total Biflavonoids Extract from Selaginella doederleinii by HPLC-QTOF-MS and Its In Vitro and In Vivo Anticancer Effects. Molecules. 2017;22(2):325-41.

21. Chiu SC, Chiu TL, Huang SY, Chang SF, Chen SP, Pang CY, Hsieh TF. Potential therapeutic effects of $\mathrm{N}$-butylidenephthalide from radix Angelica Sinensis (Danggui) in human bladder cancer cells. BMC Complement Altern Med. 2017:17(1):523.

22. Yu J, Thomson TC, Johnson J. Cross talk between estradiol and mTOR kinase in the regulation of ovarian granulosa proliferation. Reprod Sci. 2012; 19(2):143-51.

23. Xiang $X$, Zhao J, Xu G, et al. MTOR and the differentiation of mesenchymal stem cells. Acta Biochim Biophys Sin Shanghai. 2011;43(7):501-10.

24. Lin JF, Tsai TF, Liao PC, et al. Benzyl isothiocyanate induces protective autophagy in human prostate cancer cells via inhibition of mTOR signaling. Carcinogenesis. 2013;34(2):406-14.

25. Pignochino Y, Dell'aglio C, Basirico M, et al. The combination of Sorafenib and Everolimus abrogates mTORC1 and mTORC2 upregulation in osteosarcoma preclinical models. Clin Cancer Res. 2013;19(8):2117-31.

26. Heitman J, Movva NR, Hall MN. Targets for cell cycle arrest by the immunosuppressant rapamycin in yeast. Science. 1991:253(5022):905-9.

27. Sarbassov DD, Ali SM, Sengupta $S$, et al. Prolonged rapamycin treatment inhibits mTORC2 assembly and Akt/PKB. Mol Cell. 2006:22(2):159-68.

28. Steelman LS, Chappell WH, Abrams SL. Roles of the Raf /MEKJERK and PI3K PTEN/Akt/mTOR pathways in controlling growth and sensitivity to therapyimplications for cancer and aging. Aging (Albany NY). 2011;3(3):192-222.

29. Kang GH, Lee BS, Lee ES, et al. Prognostic significance of p53, mTOR, c-met, IGF-1R, and HSP70 overexpression after the resection of hepatocellular carcinoma. Gut Liver. 2014:8(1):79-87.

30. Hu J, Fang Y, Cao Y, et al. MiR-449a regulates proliferation and chemosensitivity to cisplatin by targeting cyclin D1 and BCL2 in SGC7901 cells. Dig Dis Sci. 2014;59(2):336-45.

31. Stegh AH, Brennan C, Mahoney JA, et al. Glioma oncoprotein BCI2L12 inhibits the p53 tumor suppressor. Genes Dev. 2010;24(19):2194-204.

32. Taghavi MS, Akbarzadeh A, Mahdian R, et al. Cisplatin downregulates BCL2L12, a novel apoptosisrelated gene, in glioblastoma cells. In Vitro Cell Dev Biol Anim. 2013;49(6):465-72

33. Foutadakis $\mathrm{S}$, Avgeris M, Tokas T, et al. Increased BCL2L12 expression predicts the short-term relapse of patients with TaT1 bladder cancer following transurethral resection of bladder tumors. Urol Oncol. 2014;32(1):39-42.

34. Wu L, Liu X, Wang L, et al. Exendin-4 protects HUVECs from tunicamycininduced apoptosis via inhibiting the IRE1a/JNK/caspase-3 pathway. Endocrine. 2017:55(3):764-72. 